Sabit ortodontik tedavinin sıralama ve seviyeleme safhasında kullanılan mini vida desteğinin etkilerinin incelenmesi

\section{Evaluation of effects of mini screw anchorage during leveling and alignment phase of fixed orthodontic treatment}

\section{Yrd. Doç. Dr. Nurhat Özkalaycı}

Bülent Ecevit Üniversitesi, Diş Hekimliği Fakültesi, Ortodonti Anabilim Dalı, Zonguldak

Geliş Tarihi : 30 Ekim 2015

Kabul Tarihi : 22 Şubat 2016

\section{Yazışma adresi:}

Yrd. Doç. Dr. Nurhat Özkalaycı

Bülent Ecevit Üniversitesi Diş Hekimliği Fakültesi, Ortodonti Anabilim Dalı

Esenköy, Kozlu, Zonguldak

Tel: 03722613600

Faks: 03722613603

E-mail: dt.nurhat@yahoo.com
ÖZET

Amaç: Çalışmanın amacı sabit ortodontik tedavi sürecinin siralama ve seviyeleme fazında kullanılan mini vida desteğinin etkilerinin incelenmesidir.

Gereç ve yöntem: Şiddetli dişsel çapraşı|klığı olan yirmi hasta çalışmaya dahil edilmiştir. Tüm hastalar iskeletsel sınıf I ilişkiye ve dişsel sınıf I molar ilişkiye sahiptiler. Hastaların yarısında ortodontik mini vidalar alt birinci azı diş ile ikinci küçük azı diş arasına çift taraflı olarak yerleştirildiler. Diğer on hastada ise vidalar üst birinci büyük azı diş ile ikinci küçük azı diş arasına çift taraflı olarak konuldu. Tüm hastalarda vidaların olmadığı çenelerde intiyaç duyulan desteğin sağlanması için sınıf II ve Sınıf III lastikler kullanıldı. Tedavinin başında ve sonunda, ortodontik kayıtlar alındı. Tedavinin ilk üç ayında ayllk olarak uygulanan kuvvet miktarı ve diş hareket miktarı ölçüldü ve ayrıntılı incelendi. İslem öncesi ve sonrası veriler istatistiksel olarak karşılaştıııldı.

Bulgular: Işlem öncesi ve sonrası yapılan sefalometrik ölçümlerin istatistiksel olarak karşılaştırıması anlamlı bir değişiklik göstermedi. Hem kapalı yayların hem de lastiklerin oluşturdukları kuvvetler seviyeleme ve sıralama fazı süresince azaldı. Kapalı yaylar elastiklere nazaran daha fazla kuvvet üretiyorlardı. Sağ ve sol tarafta meydana gelen diş hareket miktarları birbirinden istatistiksel olarak farklı değildi. Alt ve üst çene arasında diş hareket miktarı bakımından istatistiksel olarak anlamlı farklılklar tespit edilmez iken kuvvet miktar ı ikiçene arasında karşılaştıııldığında istatistiksel olarak anlamlı farklılklar görüldü.

Sonuç: Destek amacıyla mini vida kullanımı başarılı bir süreç sağlamaktadır. Sınıf II ve Sınıf III çeneler arası lastikler seviyeleme ve sıralama safhasında yeterli kuvveti oluşturmada başarılıar. Kapalı yaylar ile lastiklerin oluşturdukları kuvvet miktarları arasında farklılıklar olmakla birlikte oluşturdukları diş hareket miktarları arasında anlamlı farkllıklar mevcut değildir.

Anahtar Kelimeler: Mini vida, destek, sıralama ve seviyeleme, kuvvet.

\section{SUMMARY}

Aim: The aim of this study is to evaluate the effects of the mini screw anchorage during leveling and alignment phase of the fixed orthodontic treatments.

Materials and methods: Twenty patients with severe dental crowding were included to study. All of the patients have Skeletal Class I relationship and Class I dental molar relationship. Orthodontic mini screws were inserted between lower first molar and lower second premolar bilaterally at half of patients. The other ten patients have two mini screws between upper first molar and second premolar bilaterally. Class II and Class III inter-maxillary elastics were used to provide adequate anchorage on jaws 
without mini screws. At the beginning of the treatment and at the end of the treatment, orthodontic records were taken. Amount of applied force and amount of tooth movement were measured during first four months of treatment and analyzed in detail. Pretreatment and posttreatment records were statistically compared.

Results: Statistical comparison of cephalometric measurements made before and after procedure showed that no statistical differences. Both of forced of closed coils and elastics were decreased during leveling and alignment phase. Closed coils produced more forces than elastics There are notany statistically significant differences between amounts of tooth movements on right and left sides. One one hand no significant differences were detected between upper and lower jaw according to tooth movement on the other hand significant differences were seen between force levels of upper and lower jaws.

Conclusions: Usage of orthodontic mini screw for anchorage is a succesful process. Class \| and Class ॥| intermaxillary elastics can provide adequate orthodontic force during leveling and alignment phase. There are differences between force levels of closed coils and elastics However, there are no significant effect of this difference on amount of tooth movement.

Keywords: Mini screw, anchorage, leveling and alignment, force

\section{GiRiş}

Düzeltici ortodontik tedaviler; fonksiyonel tedaviler ortopedik müdahaleler, hareketli apareyler ile yapılanlar ve sabit ortodontik tedaviler olmak üzere temelde dört ana başlık altında toplanabilirler. Sabit ortodontik tedaviler; çekimli ve çekimsiz olmak üzere iki ana gruba ayrılırlar Çekimsiz sabit ortodontik tedavilerde gerekli düzeltmelerin yapılabilmesi için gerekli yer intiyacı diş eksiltmeksizin sağlanabilmekte iken çekimli sabit ortodontik tedavilerde çapraşıklık gibi problemleri çözmek amacıyla diş çekimi gerekmektedir. Bu çekilen dişler çok büyük oranda birinci küçük azı dişlerdir. Çekilecek olan diş sayısını ve yerini, çapraşıklığın mevcut olduğu bölge, azı dişi kapanışı, köpek dişi kapanışı ve orta hat kayması gibi faktörler belirlemektedir. Çekimli vakaların çok büyük bir bölümünde genellikle üst birinci küçük azı dişlerinin çift taraflı çekim veya alt ve üst birinci küçük azı dişlerin çift taraflı çekimi planlanmaktadır ${ }^{1}$ Çekimli tedaviye karar verilen vakalarda karar verilmesi gereken bir diğer faktör ise destek ya da çapa planlamasıdır. Destek planlaması temelde; En yüksek (maksimum), orta (modarate), en az (minimum) ve kesin (absolute) olmak üzere dört tanımlamayla planlanır. Kesin destek tanımlama olarak bazı zıt görüşlere rağmen destek sağlayan elemanın hiç hareket etmemesi ile oluşturulur.'
Bu elemanlar ortodontik mini vidalardır. Mini vidalar yerleştirildikleri kemik bölgesine mekanik olarak tutunurlar ve görevlerini tamamladıktan sonra istenildikleri zaman yerleştirildikleri bölgeden çıkarılabilen destek elemanlarıdır Düz tel tekniğinin tedavi metodu olarak kullanıldığı sabit ortodontik tedavilerde ve ön bölgede şiddetli çapraşıklığın görüldüğü vakalarda seviyeleme ve sıralama aşamasında destek sağlamak amacıyla mini vidalar kullanılmaktadır.2-4 Bu uygulamalarla köpek dişlerine uygulanan kuvvetlerle keserlerde meydana gelebilecek ileri itimin azaltılması ya da engellenmesi planlanmaktadır

Yapılan çalışmada mini vidalar hastaların yarısında üst çeneye diğer yarısında ise alt çeneye uygulanmış ve destek elemanı olarak kullanılmıştır. Kuvvet oluşturmak amacıyla kapalı yaylar ve lastikler kullanıımıştır. Çalışmada diş hareket miktarları, kuvvet miktarları ve yan kafa radyografileri üzerinde yapılan ölçümler ayrıntıı değerlendirilmiş ve tedavi sürecinde görülen değişiklikler irdelenmiştir.

\section{GEREÇ VE YÖNTEM}

Çalışmaya 12- 16 yaş arası yirmi hasta dâhil edildi. Hastaların tümünde iskeletsel sınıf I kapanış bozukluğu mevcuttu ve ön dişlerde özelliklede köpek dişleri bölgesinde şiddetli çapraşıklık görülmekteydi (Resim 1). Yirmi yaş dişleri hariç tüm daimi dişler mevcuttu ve herhangi bir diş kaybı yoktu. Alınan sistemik hikâyelerinde ortodontik tedavide önem teşkil edecek tedaviye etkisi olacak herhangi bir hastalık bulgusu, geçirilmiş hastalık beyanı ve ilaç kullanımı yoktu Tedavi planlamalarında üst ve alt birinci küçük azı dişlerin çekimine karar verilmişti. Destek olarak sonsuz destek planlaması yapılmıştı ve mini vida kullanımına uygun

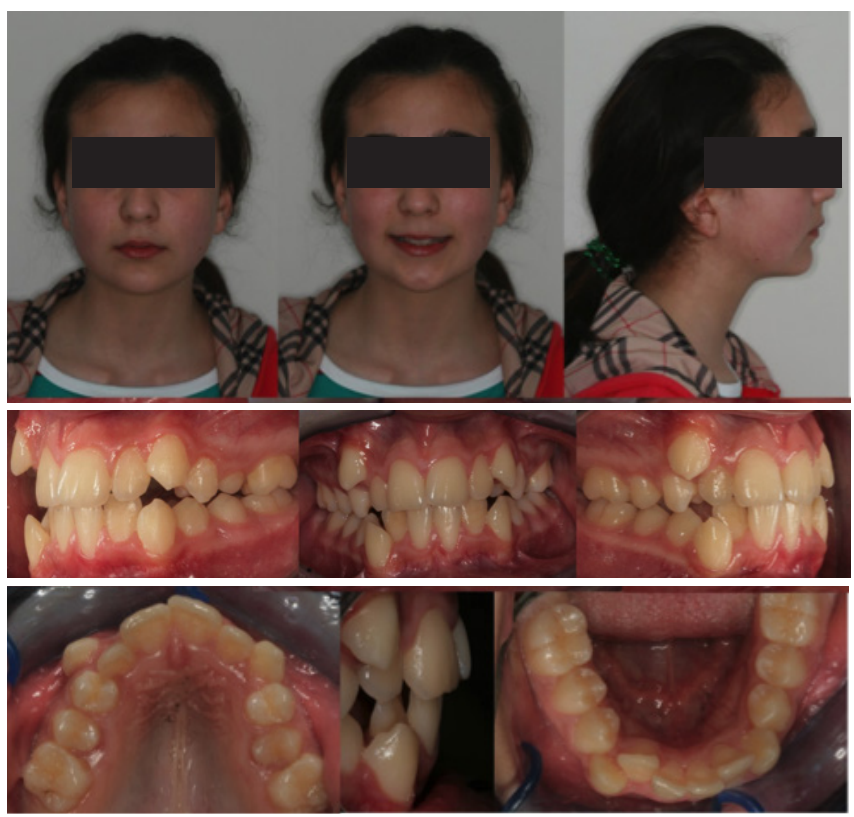

Resim 1: Tedavi öncesi hastanın ağız dışı ve ağız içi görüntüleri 
hastalardı. Hastaların tedavi başı kayıtları olarak; sistemik ve dişsel hikâyeler, ağız içi ve ağız dışı fotoğraflar, tüm çene ve ortodontik ölçümlere olanak tanıyan yan kafa radyografiler, ortodontik ölçülerden elde edilmiş ortodontik alçı diş modelleri mevcuttu.

Hastaların tümüne sabit ortodontik mekanik olarak aynı tip ve marka braketler yapıştırılmış ve aynı kalınlıkta ve özellikte ortodontik ark telleri aynı sırayla yerleştirilmişti. Hastalarda kullanılan tüm mini vidalar, kapalı yaylar ve elastikler aynı marka ve aynı özellikte idi. Hastaların yarısında mini vidalar üst çeneye çift taraflı olarak ikinci küçük azı ile birinci büyük azı diş arasına yerleştirilmişti. Bu hastalarda üst köpek dişlere kuvvet uygulamak amacıyla kapalı yaylar kullanırken alt köpek dişlere kuvvet uygulamak amacıyla çeneler arası lastikler kullanılmıştı. Lastiklerin ve yayların bir ucu mini vidaya takıııken diğer uçları köpek dişi braketindeki çengele takılmaktaydı. Hastaların diğer yarısında mini vidalar alt ikinci küçük azı diş ile birinci büyük azı diş arasına yerleştirilmişti ve yine alt köpek dişlerine kuvvet uygulamak için kapalı yaylar üst köpek dişlerine kuvvet uygulamak için çeneler arası lastikler kullanımıştı. Lastiklerin ve kapalı yayların bağlanmasında diğer hasta grubuyla aynı yöntem takip edilmişti (Resim 2). Çalışmada mini vida tepesindeki sabit referans noktası ile köpek dişi braketindeki çengelin ucu
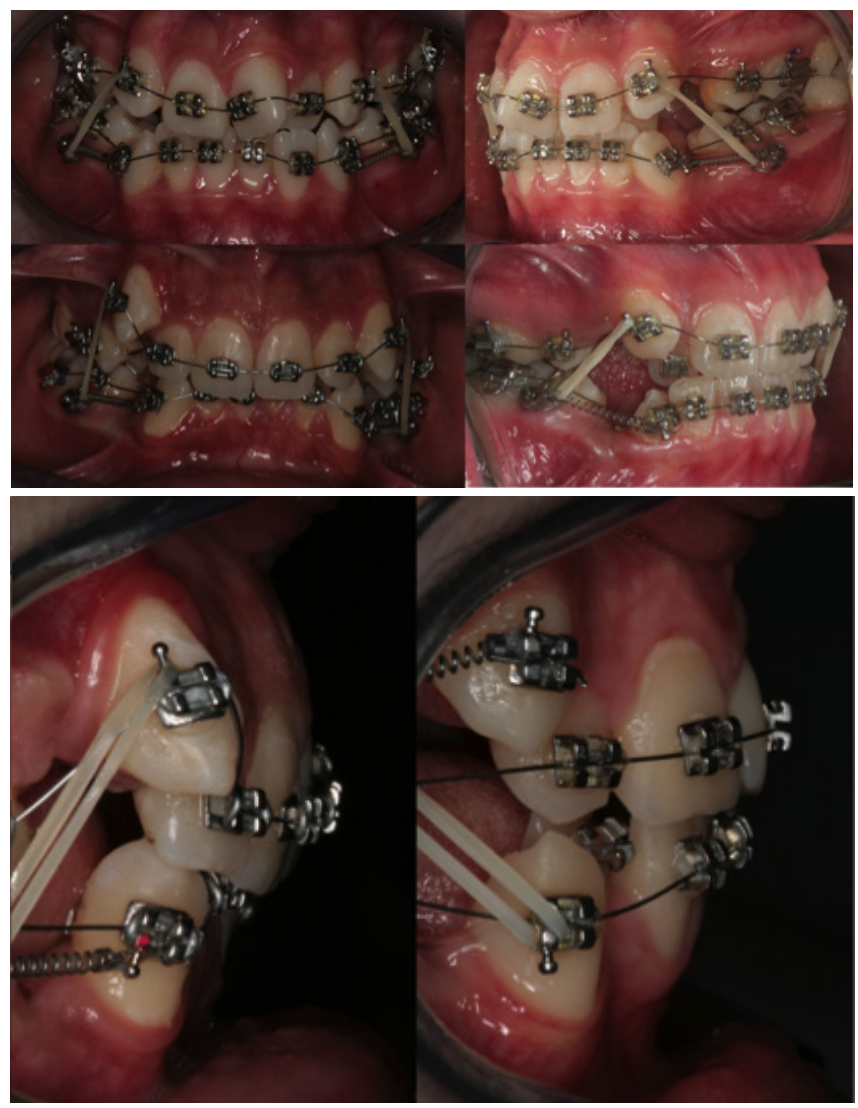

Resim 2: Mini vida, yay ve lastik uygulamaları arasındaki mesafe tedavinin ilk randevusundan başlanmak üzere aylık olarak 4 defa bir başka ifadeyle 3 ay sürecince ölçüldü. Bu süreçte lastiklerin ve kapalı yayların oluşturdukları kuvvetlerde kuvvetölçer yardımıyla takip edildi. Dolayısıyla hem alt köpek dişi hem de üst köpek dişinde görülen hareket miktarları hesaplandı. Elde edilen bulgular incelendi ve karşılaştırıldı. Ilerleyen süreçte hastalardan işlem sonunda alınan yan kafa radyografilerinde ortodontik ölçümler yapıldı. Elde edilen veriler ayrıntıı incelendi ve birbirleriyle karşılaştırıld. İstatistiksel analiz için Bağımlı Örneklem testi SPSS 16,0 programı kullanılarak yapıldı.

\section{BULGULAR}

Hastalardan 1 tanesi mini vida kayıpları sonrası tekrar mini vida yerleştirilmesini kabul etmediği için çalışmadan çıkartıldı. Bir hasta tedavisini sonlandırma talebinde bulunduğu için dosyası değerlendirme dışı bırakıldı. Dosya incelemesinde tedavi sürecinde görülen sistemik hastalıklardan dolayı 2 hastanın kayıtları çalışma dışı bırakıldı. On alı hastanın dosya incelemesinden elde edilen bulgularda mini vida kullanım süresinin ortalama 5 ay olduğu görüldü ve sınırlı sayıdaki örnek ışığında en çok mini vida tutuculuk kaybının sağ alt bölgede görüldüğü tespit edildi. Kuvvet uygulama elemanlarının mini vida tepesinden kullanımının herhangi bir probleme sebep olmadığı izlendi. Mini vidaların baş kısmına yerleştirilen çengellerin lastik kullanımı için uygun bir yapı oluşturduğu gözlendi. Hastaların tümünde mini vidaların yeterli desteği sağladığı tespit edildi.

Hastalarda ilk 3 ayda yapılan ölçümlerde kapalı yayların oluşturduğu kuvvetlere ait değişim miktarı ile lastiklerin oluşturduğu kuvvetlerin değişim miktarları sağ ve sol taraf olmak üzere Şekil 1'de görülmektedir.

Ortalama \%30-40 dolayında bir kuvvet azalması görülmektedir. Vida ile köpek dişler arası mesafe değişimleri

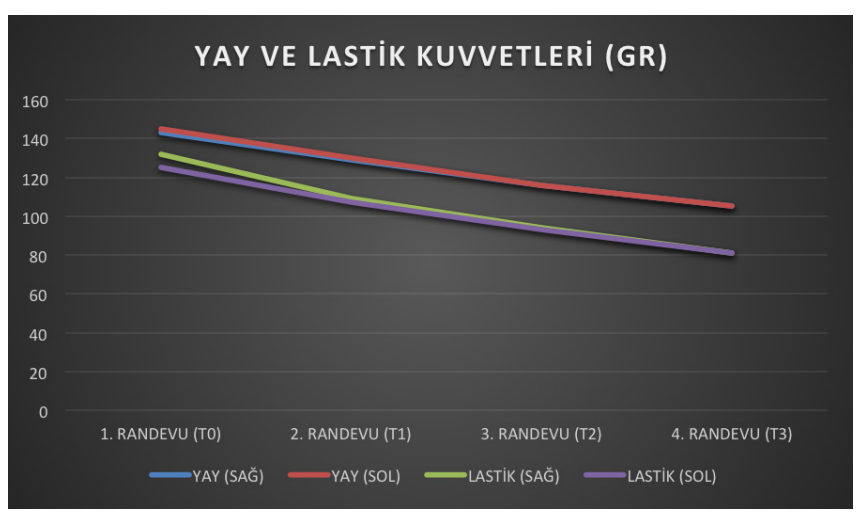

Şekil 1: Yay ve lastikler tarafından oluşturulan kuvvetin zamanla değişiminin gösterimi 


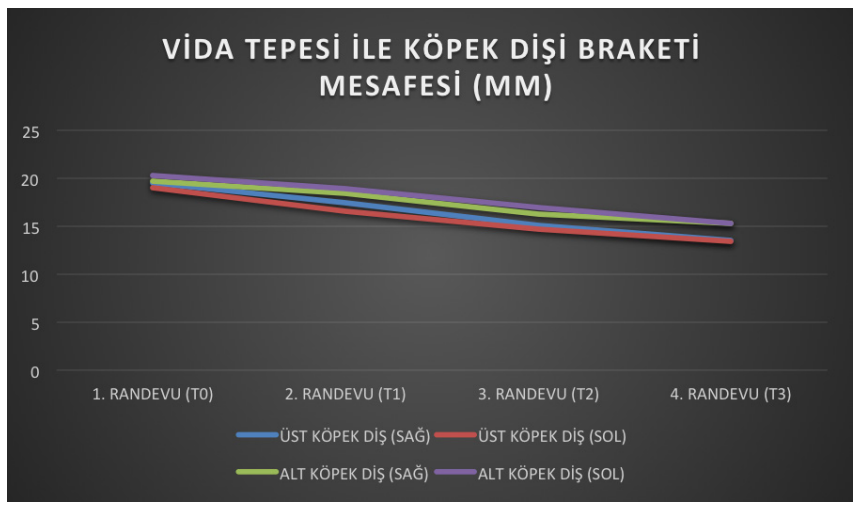

Şekil 2: Vida tepesi ile köpek dişi braketi arasındaki uzunluğun değişiminin gösterimi

ki bu aynı zamanda diş hareket miktarını yansıtmaktadır Şekil 2'de gösterilmiştir. Yan kafa radyografileri üzerinde yapılan analizlerden elde edilen sonuçlar ışığında işlem öncesi ve işlem sonrası değerler arasında korelasyon anlamlı bulunurken istatistiksel olarak anlamlı bir fark gözlenmemiştir (Tablo1, Tablo 2, Tablo 3).

Hastaların sağ ve solları hem uygulanılan kuvvet hem de diş hareket miktarı açısından karşılaştırıldığında istatistiksel olarak anlamlı bir farklıık tespit edilmemiştir (Tablo 4, Tablo 5). Alt ve üst çenede dişlerin maruz kaldığı kuvvet miktarları birbirinden istatistiksel olarak farklı iken diş hareket miktarlarında anlamlı farklıık görülmemiştir (Tablo 6, Tablo 7).

\begin{tabular}{|c|c|c|c|c|c|}
\hline \multicolumn{6}{|c|}{ Bağımlı Örneklem-Tanımlayıcı İstatistikler } \\
\hline & & Mean & $N$ & Std. Deviation & Std. Error Mean \\
\hline \multirow{2}{*}{ Pair 1} & SNA TO & 76,8571 & 16 & 3,61316 & ,96566 \\
\hline & SNA T1 & 76,5714 & 16 & 3,47993 & ,93005 \\
\hline \multirow{2}{*}{ Pair 2} & SNB TO & 73,7143 & 16 & 3,49568 & ,93426 \\
\hline & SNB T1 & 73,6429 & 16 & 3,69214 & .98676 \\
\hline \multirow{2}{*}{ Pair 3} & ANB TO & 3,1429 & 16 & 1,56191 & .41744 \\
\hline & ANB T1 & 3,0000 & 16 & 2,0381 &, 5447 \\
\hline \multirow{2}{*}{ Pair 4} & Üst keser açısı T0 & 108,2143 & 16 & 4,93307 &, 31842 \\
\hline & Üst kesre açısı T1 & 106,8571 & 16 & 4,41775 &, 18069 \\
\hline \multirow{2}{*}{ Pair 5} & Alt keser açısı T0 & 90,6429 & 16 & 7,64206 & .04243 \\
\hline & Alt keser açısı T1 & 90,6429 & 16 & 7,21758 & ,92898 \\
\hline \multirow{2}{*}{ Pair 6} & Keserlerarası Açı T0 & 128,8571 & 16 & 7,29444 & ,94952 \\
\hline & Keserlerarası Açı T1 & 130,9286 & 16 & 6,83277 & 82614 \\
\hline \multirow{2}{*}{ Pair 7} & Çenelerarası Açı TO & 23,0714 & 16 & 5,64956 &, 50991 \\
\hline & Çenelerarası Açı T1 & 24,0000 & 16 & 5,49125 &, 4676 \\
\hline \multirow{2}{*}{ Pair 8} & SN-Alt çene Açı TO & 39,4286 & 16 & 7,75306 &, 07209 \\
\hline & SN-Alt çene Açı T1 & 39,5000 & 16 & 7,12255 & ,90358 \\
\hline
\end{tabular}

Tablo 1: Yan kafa radyografileri üzerinde yapılan ortodontik ölçümlerden elde edilen veriler

\begin{tabular}{|c|c|c|c|c|}
\hline \multicolumn{5}{|c|}{ Bağımlı Örneklem-Korelasyonlar } \\
\hline & & $N$ & Correlation & Sig. \\
\hline Pair 1 & SNA TO \& SNA T1 & 16 &, 955 &, 000 \\
\hline Pair 2 & SNB TO \& SNB T1 & 16 & 969 &, 000 \\
\hline Pair 3 & ANB TO \& ANB T1 & 16 & .894 &, 000 \\
\hline Pair 4 & Üst keser açısı T0 \& Üst kesre açısı T1 & 16 &, 743 &, 002 \\
\hline Pair 5 & Alt keser açısı T0 \& Alt keser açısı T1 & 16 & 917 & .000 \\
\hline Pair 6 & Keserlerarası Açı T0 \& Keserlerarası Açı T1 & 16 & 631 & 0,016 \\
\hline Pair 7 & Çenelerarası Açı T0 \& Çenelerarası Açı T1 & 16 &, 650 & 0,012 \\
\hline Pair 8 & SN-Alt çene Açı TO \& SN-Alt çene Açı T1 & 16 & 922 &, 000 \\
\hline
\end{tabular}

Tablo 2: Ortodontik ölçümlerin işlem öncesi ve işlem sonrası korelasyonunun değerlendirilmesine ilişkin veriler 


\begin{tabular}{|c|c|c|c|c|c|c|c|c|c|}
\hline \multicolumn{10}{|c|}{ Bağımlı Örneklem Testi } \\
\hline & & \multicolumn{5}{|c|}{ Paired Differences } & \multirow{3}{*}{$\mathrm{t}$} & \multirow{3}{*}{ df } & \multirow{3}{*}{ Sig } \\
\hline & & \multirow[t]{2}{*}{ Mean } & \multirow[t]{2}{*}{ Std. Deviation } & \multirow[t]{2}{*}{ Std. Error Mean } & \multicolumn{2}{|c|}{$\begin{array}{l}\text { 95\% Confidence Interval of } \\
\text { the Difference }\end{array}$} & & & \\
\hline & & & & & Lower & Upper & & & \\
\hline Pair 1 & SNA TO \& SNA T1 & , 28571 & 1,06904 & ,28571 &,- 33153 &, 90296 & 1,00 & 15 &, 336 \\
\hline Pair 2 & SNB TO \& SNB T1 & .07143 & 91687 & 24505 &,- 45796 &, 60082 & .291 & 15 & .775 \\
\hline Pair 3 & ANB TO \& ANB T1 &, 14286 & ,94926 &, 2537 &,- 40523 &, 69094 &, 563 & 15 &, 583 \\
\hline Pair 4 & $\begin{array}{l}\text { Üst keser açısı T0 } \\
\text { \& Üst kesre açısı T1 }\end{array}$ & 1,35714 & 3,38792 & 90546 &,- 59899 & 3,31327 & 1,499 & 15 &, 158 \\
\hline Pair 5 & $\begin{array}{l}\text { Alt keser açısı T0 } \\
\text { \& Alt keser açısı T1 }\end{array}$ &, 00000 & 3,06343 &, 81874 & $-1,76877$ & 1,76877 & .000 & 15 & 1,000 \\
\hline Pair 6 & $\begin{array}{c}\text { Keserlerarası Açı T0 } \\
\text { \& Keserlerarası Açı } \\
\text { T1 }\end{array}$ & $-2,07143$ & 6,08231 & 1,62557 & $-5,58325$ & 1,44039 & $-1,274$ & 15 &, 225 \\
\hline Pair 7 & $\begin{array}{c}\text { Çenelerarası Açı T0 } \\
\text { \& Çenelerarası Açı } \\
\text { T1 }\end{array}$ &,- 92857 & 4,66516 & 1,24682 & $-3,62216$ & 1,76501 &,- 745 & 15 & .470 \\
\hline Pair 8 & $\begin{array}{l}\text { SN-Alt çene Açı TO\& } \\
\text { SN-Alt çene Açı T1 }\end{array}$ &,- 07143 & 2,99908 & 80154 & $-1,80305$ & 1,66019 &,- 089 & 15 & ,930 \\
\hline
\end{tabular}

Tablo 3: Işlem öncesi ve işlem sonrası yapılan ortodontik ölçümlerden elde edilen verilerin kıyaslanması

\begin{tabular}{|c|c|c|c|c|c|c|c|c|c|}
\hline \multicolumn{10}{|c|}{ Bağımlı Örneklem Testi } \\
\hline & & \multicolumn{5}{|c|}{ Paired Differences } & \multirow[t]{3}{*}{$\mathrm{t}$} & \multirow[t]{3}{*}{ df } & \multirow[t]{3}{*}{ Sig } \\
\hline & & \multirow[t]{2}{*}{ Mean } & \multirow{2}{*}{$\begin{array}{c}\text { Std. } \\
\text { Deviation }\end{array}$} & \multirow{2}{*}{$\begin{array}{l}\text { Std. Error } \\
\text { Mean }\end{array}$} & \multicolumn{2}{|c|}{$\begin{array}{c}\text { 95\% Confidence Interval } \\
\text { of the Difference }\end{array}$} & & & \\
\hline & & & & & Lower & Upper & & & \\
\hline Pair 1 & YAY SAĞ-SOL TO & $-1,15385$ & 16,09268 & 4,46331 & $-10,87856$ & 8,57086 & -259 & 15 & 800 \\
\hline Pair 2 & YAY SAĞ-SOL T1 &,- 76923 & 12,88509 & 3,57368 & $-8,55561$ & 7,01715 & -215 & 15 & 833 \\
\hline Pair 3 & YAY SAĞ-SOL T2 &, 38462 & 10,69687 & 2,96678 & $-6,07944$ & 6,84867 &, 130 & 15 & 899 \\
\hline Pair 4 & YAY SAĞ-SOL T3 &,- 38462 & 8,28189 & 2,29698 & $-5,38931$ & 4,62008 &,- 167 & 15 & 870 \\
\hline Pair 5 & $\begin{array}{c}\text { LASTIK SAĞ-SOL } \\
\text { TO }\end{array}$ & 6,53846 & 14,19868 & 3,93801 & $-2,04172$ & 15,11864 & 1,660 & 15 &, 123 \\
\hline Pair 6 & $\begin{array}{c}\text { LASTIK SAĞ-SOL } \\
\text { T1 }\end{array}$ & 2,30769 & 9,04051 & 2,50739 & $-3,15543$ & 7,77082 &, 920 & 15 & 376 \\
\hline Pair 7 & $\begin{array}{c}\text { LASTIK SAĞ-SOL } \\
\text { T2 }\end{array}$ & 1,53846 & 8,00641 & 2,22058 & $-3,29976$ & 6,37669 & ,693 & 15 &, 502 \\
\hline Pair 8 & $\begin{array}{c}\text { LASTIK SAĞ-SOL } \\
\text { T3 }\end{array}$ & ,00000 & 6,45497 & 1,79029 & $-3,9007$ & 3,9007 &, 000 & 15 & 1,000 \\
\hline
\end{tabular}

Tablo 4: Kapalı yayların ve lastiklerin oluşturduğu kuvvetin sağ ve sol taraf karşılaştırması

\begin{tabular}{|c|c|c|c|c|c|c|c|c|c|}
\hline \multicolumn{10}{|c|}{ Bağımlı Örneklem Testi } \\
\hline & & \multicolumn{5}{|c|}{ Paired Differences } & \multirow{3}{*}{ t } & \multirow{3}{*}{ Df } & \multirow{3}{*}{ Sig. } \\
\hline & & \multirow{2}{*}{ Mean } & \multirow{2}{*}{ Std. Deviation } & \multirow{2}{*}{ Std. Error Mean } & \multicolumn{2}{|c|}{ 95\% Confidence Interval of the Difference } & & & \\
\hline & & & & & Lower & Upper & & & \\
\hline Pair 1 & UST KÖPEK DIŞ SAG-SOL TO & .42385 & 2,59113 & .71865 & $-1,14196$ & 1,98965 & .590 & 15 & .566 \\
\hline Pair 2 & ÜST KÖPEK DIŞ SAĞ-SOL T1 & 83231 & 2,7667 & ,76734 & -83959 & 2,50421 & 1,085 & 15 & .299 \\
\hline Pair 3 & UST KOPEKK DIŞ SAG-SOL T2 &, 38846 & 2,32014 & 64349 & $-1,01359$ & 1,79051 & 604 & 15 & .557 \\
\hline Pair 4 & UST KÖPEK DIŞ SAĞ-SOL T3 & .09308 & 2,48475 & 68915 & $-1,40844$ & 1,5946 & .135 & 15 & .895 \\
\hline Pair 5 & ALT KÖPEK DISS SAĞ-SOL TO & -67308 & 2,52901 & .70142 & $-2,20134$ & 85519 &,- 960 & 15 & .356 \\
\hline Pair 6 & ALT KÖPEK DIŞ SAĞ-SOL T1 &,- 52692 & 2,58151 &, 71598 & $-2,08691$ & 1,03307 &,- 736 & 15 & .476 \\
\hline Pair 7 & ALT KÖPEK DIŞS SAĞ-SOL T2 & -68692 & 2,54163 & .70492 & $-2,22282$ & 84897 &,- 974 & 15 & .349 \\
\hline Pair 8 & ALT KÖPEK DIŞ SAĞ-SOL T3 &,- 03462 & 3,41603 & 94744 & $-2,0989$ & 2,02967 & -037 & 15 & .971 \\
\hline
\end{tabular}

Tablo 5. Alt ve üst köpek dişinin sağ ve sol taraf arası hareketinin karşılaştırılması 


\begin{tabular}{|c|c|c|c|c|c|c|c|c|c|}
\hline \multicolumn{10}{|c|}{ Bağımlı Örneklem Testi } \\
\hline & & \multicolumn{5}{|c|}{ Paired Differences } & \multirow{3}{*}{ t } & \multirow{3}{*}{ Df } & \multirow{3}{*}{ Sig } \\
\hline & & \multirow[t]{2}{*}{ Mean } & \multirow[t]{2}{*}{ Std. Deviation } & \multirow[t]{2}{*}{ Std. Error Mean } & \multicolumn{2}{|c|}{$\begin{array}{l}\text { 95\% Confidence Interval of } \\
\text { the Difference }\end{array}$} & & & \\
\hline & & & & & Lower & Upper & & & \\
\hline Pair 1 & $\begin{array}{c}\text { ÜST-ALT KÖPEK DIŞ } \\
\text { SAĞTO } \\
\end{array}$ &,- 20308 & 5,82323 & 1,61507 & $-3,72202$ & 3,31587 &,- 126 & 15 & 902 \\
\hline Pair 2 & $\begin{array}{l}\text { ÜST-ALT KÖPEK DIŞ } \\
\text { SAĞT1 }\end{array}$ &,- 99538 & 5,54132 & 1,53689 & $-4,34397$ & 2,3532 &,- 648 & 15 &, 529 \\
\hline Pair 3 & $\begin{array}{l}\text { ÜST-ALT KÖPEK DIŞ } \\
\text { SAĞT2 }\end{array}$ & $-1,29077$ & 5,61795 & 1,55814 & $-4,68566$ & 2,10412 &,- 828 & 15 & .424 \\
\hline Pair 4 & $\begin{array}{l}\text { ÜST-ALT KÖPEK DIŞ } \\
\text { SAĞT3 }\end{array}$ & $-1,81846$ & 4,90839 & 1,36134 & $-4,78457$ & 1,14765 & $-1,336$ & 15 & ,206 \\
\hline Pair 5 & $\begin{array}{l}\text { ÜST-ALT KÖPEK DIŞ } \\
\text { SOL TO }\end{array}$ & $-1,30000$ & 4,67144 & 1,29562 & $-4,12292$ & 1,52292 & $-1,003$ & 15 & ,335 \\
\hline Pair 6 & $\begin{array}{l}\text { ÜST-ALT KÖPEK DIŞ } \\
\text { SOLT1 }\end{array}$ & $-2,35462$ & 4,69268 & 1,30151 & $-5,19037$ &, 48114 & $-1,809$ & 15 &, 096 \\
\hline Pair 7 & $\begin{array}{l}\text { ÜST-ALT KÖPEK DIŞ } \\
\text { SOLT2 }\end{array}$ & $-2,36615$ & 5,65803 & 1,56926 & $-5,78527$ & 1,05296 & $-1,508$ & 15 &, 157 \\
\hline Pair 8 & $\begin{array}{l}\text { ÜST-ALT KÖPEK DIŞ } \\
\text { SOLT3 }\end{array}$ & $-1,94615$ & 5,77174 & 1,60079 & $-5,43398$ & 1,54167 & $-1,216$ & 15 & 247, \\
\hline
\end{tabular}

Tablo 6: Aynı taraftaki alt ve üst köpek dişinin hareketinin karşılaştırılması

\section{Bağımlı Örneklem Testi}

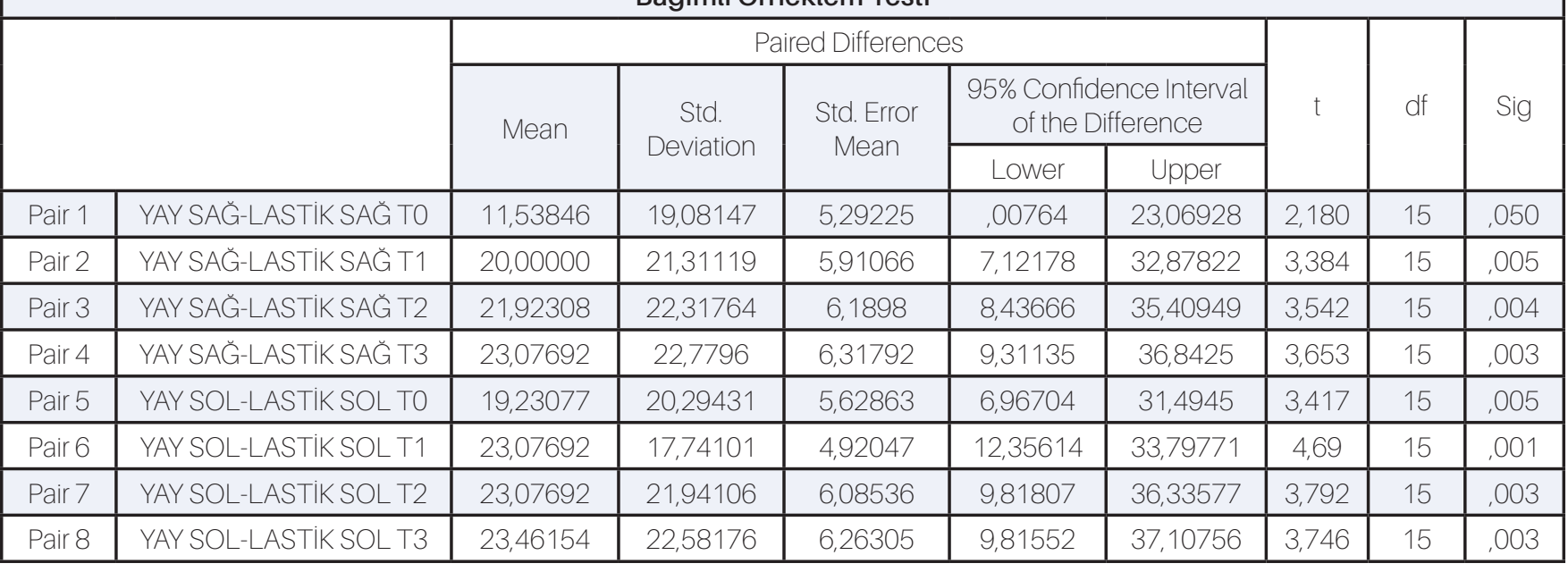

Tablo 7: Yay ve lastiklerin oluşturdukları kuvvetlerin karşılaştırması

\section{TARTISSMA}

Sabit ortodontik tedavilerde diğer yer kazanma yöntemlerinin yetersiz kaldığı durumlarda diş çekimi ile yer sağlama uzun yıllardan beri uygulanmaktadır. Genellikle de çekilen dişler birinci küçük azı dişleri olmaktadır. Bu çekimlerden elde edilen yerler ön bölgede çapraşıklığın yoğunlaştığı vakalarda çekim boşluğunun arkasında kalan dişler tarafından doldurulması görülebilmekte ${ }^{5}$ bu duruma destek kaybı denilmektedir. ${ }^{6}$ Destek kaybının görüldüğü vakalarda ön bölgedeki çapraşıklık çözülememekte ya da çözülmesi için ön dişlerin normalden çok daha fazla öne açılanmasına ihtiyaç duyulmaktadır. Sağlıkı bir kapanışın sağlanamadığı bu istenmeyen durumun ortaya çıkmasının engellenmesinde en güncel tedavi yaklaşımı mini vida desteğinin seviyeleme ya da sıralama safhasından önce oluşturulmasıdır. Düz tel tekniğinde özellikle de MBT tanımlamasında7 istenmeyen diş hareketlerini engellemede nispeten daha iyi ${ }^{8}$ olsa bile braketler tip ve tork değerlerini sağlayacak şekilde tasarlandığından tedavinin ilk safhasından itibaren kesici dişlerde bir öne açılanma eğilimi kaçınılmaz hale gelmektedir. ${ }^{9}$ Bunun kontrol altında tutulabilmesi önem arz etmektedir. Tedavi boyunca hareket etmeyecek güvenli bir destek ünitesi olarak mini vidalar kullanılmaktadır. ${ }^{10}$ Her yarım çeneye bir adet olmak üzere genellikle dört adet birinci küçük azı dişin çekildiği vakalarda dört adet mini vida kullanılmakta ve her köpek dişe bu mini vidalardan kuvvet uygulanmaktadır. Çalışmamızda dört adet mini vida yerine iki adet mini vida kullanılmış ve diğer iki mini vidanın görevi de çeneler arası lastik kullanımı ile yerleştirilen iki vidaya verilmiştir. Uygulanan bu yöntemin 
iki temel avantajı mevcuttur; birincisi, daha ekonomik bir yöntem olması iken ikinci avantajı ise hastanın daha az girişimsel işleme maruz kalmasıdır. En büyük dezavantajı ise başarııının hasta uyumuna bağlı olmasıdır. Lastikler düzenli kullanıldığında yeterli kuvvet uygulanırken kötü hasta uyumu kötü tedavi sonuçları anlamına gelmektedir.

Çalışmadan elde edilen sonuçlar göstermiştir ki lastikler yaylara oranla ortalama $20 \mathrm{gr}$ civarında daha az kuvvet oluşturmaktadır ve bu durum çalışmaya konu olan 3 ay boyunca devam etmektedir. Ancak bu durum diş hareket miktarında ciddi bir azalmaya sebep olmamaktadır. Her ne kadar yemeklerde çıkartılsalar bile bu öğün zamanları dışında lastikler de yaylara benzer bir şekilde sürekli kuvvetler oluşturuyor olabilirler. Ya da oluşturdukları aralıklı kuvvetin etkinliği sürekli kuvvetlere yakın denilebilir. Diş hareket miktarları değerlendirildiğinde ortaya çıkan toplamda ortalama $5 \mathrm{~mm}$ bir hareket miktarı aylik $1 \mathrm{~mm}$ 'nin üzerinde bir hareket miktarına tekabül etmektedir. Bu hareket diğer çalışmalara ${ }^{11,12}$ göre nispeten daha hızlı olarak sınıflandırlabilir. Bu hareket miktarı iki temel etkenle açıklanabilir; birincisi yaptırlan hareket çoğunlukla arkaya devrilme hareketidir, ikincisi ise uygulanan kuvvet miktarı köpek diş hareketi için uygun düzeydedir denilebilir.

Sağ ve sol taraflar arasında yapılan kurvet miktarı ve diş hareket miktarı karşılaşıımalarında anlamlı farkların çıkmaması çapraşıklıkların ya da diş konumlarının çoğunlukla simetriğe yakın olmasından dolayı ortaya çıkmış olabilir.

Aynı taraftaki alt ve üst diş hareketleri arasında anlamlı farklılık yokken uygulanan kuvvetler arasında anlamlı fark çıkması aradaki kuvvet farkının diş hareketi üzerinde çok büyük bir etkisinin olmadığı şeklinde yorumlanabilir. Hem lastiklerin hem de yayların uyguladıkları kuvvet zamanla azalmışır. Buna sebep olan diş hareket miktarıdır. Dişler hareket ettikçe mini vidaya yaklaşmışlardır ${ }^{13}$ ve bu hareket kuvvet kaynağı elemanların aktivasyon miktarını azaltmışıır, bu da kuvvetin azalmasına sebep olmuştur.

Yan kafa radyografileri üzerinde yapilan ölçümler değerlendirildiğinde ortaya çıkan sonuçlar göstermektedir ki; mini vida desteğini seviyeleme sıralama aşamasından önce kullanmaya başlamak dişlerde meydana gelebilecek herhangi bir ileri açılanmayı engellemektedir. Üst keser ve alt keser açıları neredeyse hiç değişmemiş̧ir bu sadece köpek dişinde bir hareketin görüldüğü anlamına gelmekle birlikte ortodontik ölçümler en ileri dişe göre yapıldığından en ileri dişten daha geride kalan diğer kesici dişlerin de en ileri dişe doğru hareket ettiğini göstermektedir. Bu da istenilen bir durumdur. Mini vidalar uzun yıllardır kök dişi hareketleri için kullanılmaktadır. ${ }^{14}$ Çalışma özelinde kullanılan çeneler arası lastiklerin herhangi bir iskeletsel etkisinin olmadığı gözlenmektedir. Ortaya çıkan bu durum iki temel etkenle alakalı olabilir; birincisi, lastiklerin oluşturdukları kuvvet ortopedik etki düzeyinin altındadır, ikicisi ise lastik kullanımının toplam süresi böyle bir etki oluşturacak seviyenin çok altındadır.

\section{SONUÇ}

Mini vidaların düz tel tekniğinin kullanıldığı vakalarda seviyeleme ve sıralama aşamasından önce yerleştirilmeleri seçilmiş vakalarda istenilen etkiyi yaratmaktadır. Mini vida yerine lastiklerin kullanımı sunulan çalışmanın sınırları içerisinde istenilen etkiyi yaratmışıı. Gelecek çalışmalarda değişik vida tipleri, değişik yay tipleri ve değişik lastiklerin kullanılarak çalışmanın alanının genişletilmesi faydalı olacaktır. 


\section{KAYNAKLAR}

1. Proffit WR, Fields Jr HW, Sarver DM. Contemporary orthodontics. Elsevier Health Sciences. 2014

2. Davoody AR, Posada L, Utreja A, Janakiraman $N$, Neace WP, Uribe F, Nanda R. A prospective comparative study between differential moments and miniscrews in anchorage control. The European Journal of Orthodontics, 2013; 35: 568-576.

3. Nalbantgil D, Tozlu M. Ortodontide Mini Vida Kullanımı 7tepe klinik 2008; 2: 29-33.

4. Sarı E, Uçar C. Mini Vida Kullanılarak Sınıf II Divizyon 1 Malokluzyon Tedavisi. 7tepe klinik 2008; 2: 18-21

5. XU TM, Zhang X, Oh HS, Boyd RL, Korn EL, Baumrind S. Randomized clinical trial comparing control of maxillary anchorage with 2 retraction techniques. American Journal of Orthodontics and Dentofacial Orthopedics 2010; 138; 544-e1.

6. Jain A, Ray S, Mitra R, Chopra SS. Possibility of space closure without initial alignment. Journal of Indian Orthodontic Society 2015; 49: 152-152.

7. Talapaneni AK, Supraja G, Prasad M, Kommi PB. Comparison of sagittal and vertical dental changes during first phase of orthodontic treatment with MBT Vs ROTH prescription. Indian Journal of Dental Research 2012; 23: 182-186.

8. Wu LL, Zhang MM, Shao P. Comparative study of anchorage loss between straight wire appliance and standard edgewise appliance [J]. Stomatology 2007, 8. 5-9.

9. Rajesh M, Kishore MSV, Shetty KS. Comparison of anchorage loss following initial leveling and aligning using ROTH and MBT Prescription-A clinical prospective study. Journal of international oral health JIOH 2014; 6: 16-21.

10. Beycan K, Alcan T, Acar A. Early Extraction Space Closure Using Miniscrew Anchorage. Case Study and Case Report 2015; 5: 149-154.

11. Ahad M, Shafi M, Khursheed I, Shakeel M. Evaluation of Micro Implants for Absolute Anchorage: A Clinical Study Print. International Journal of Clinical Cases and Investigations 2015; 6: 52-67,

12. Reddy PA, Prabhakar R, Acharya SS, Karthikeyan MK. A clinical and radiographic study to evaluate the rate of retraction of maxillary canine using nickel-titanium closed coil spring with two different bracket systems. APOS Trends in Orthodontics 2014; 4: 169-177.

13. Sharma M, Sharma V, Khanna B. Mini-screw implant or transpalatal arch-mediated anchorage reinforcement during canine retraction: A randomized clinical trial. Journal of orthodontics 2012; 39: 102-110

14. Uyanlar A, Öztoprak MO. Sınıf I Anterior Çapraşıklık Tedavisinde Kanin Retraksiyonu Için Mini Vida Kullanımı: Olgu Sunumu. 7tepe Klinik 2009; 2: 48-50 